\section{Branching and Blind Node Incidence in Interspecific Backcross Families of Peach}

\author{
Omar Carrillo-Mendoza ${ }^{1}$, José X. Chaparro, and Jeffrey Williamson \\ Horticultural Sciences Department. University of Florida, 2121 Fifield Hall, \\ P.O. Box 110690, Gainesville FL 32611-0690
}

Additional index words. Prunus persica, P. kansuensis, P. dulcis, tree architecture, breeding, heritability, selection

\begin{abstract}
Tree size and branching control has gained importance as labor and pruning costs have increased. In addition, the occurrence of blind nodes is a critical factor that affects peach tree architecture and productivity in subtropical climates. Seven backcross families segregating for branching and blind nodes were developed using 'Flordaguard' peach $\times P$. kansuensis or 'Tardy Nonpareil' almond $F_{1}$ s backcrossed to 'AP00-30WBS', 'UFSharp', or 'UF97-47' peach selections and evaluated for branching index and blind node frequency during the winters of 2010 and 2011. P. kansuensis backcrosses presented increased branching and lower blind node incidence, whereas almond backcrosses presented less branching and higher blind node incidence, resembling the $\boldsymbol{P}$. kansuensis and almond $F_{1}$ parents, respectively. There was also broad variability for branching and blind nodes within the $\boldsymbol{P}$. kansuensis and 'Tardy Nonpareil' almond backcross families influenced by the peach parents that were used to generate the backcross populations. The moderate heritability and year-to-year correlation for these traits indicate that they are affected by the environment, but selection for reduced branching and lower blind node incidence is feasible.
\end{abstract}

Although growth forms in peach such as dwarf, pillar, weeping, and compact have been studied (Scorza et al., 2006), little effort has been devoted to the study of tree architecture and branching. The standard peach tree has vigorous acropetal growth, moderately strong apical dominance, and 1-year-old fruiting shoots, requiring fair to intensive pruning (Marini and Corelli-Grappadelli, 2006). There is additional genetic diversity for tree structure in closely related Prunus species that could be used to modify the architecture of peach trees (Scorza and Okie, 1990). For instance, the root-knot nematode-resistant rootstock 'Flordaguard', which has remarkably long pendulous branches, is a sixthgeneration descendant from a hybrid between peach and the related species $P$. davidiana C-26712 that was subsequently backcrossed to peach (Sherman et al., 1991).

P. kansuensis 'A1' trees grown in Byron, GA, are short-stature and highly branched trees. Peach $\times P$. kansuensis hybrids are vigorous and intermediate in characteristics with a higher production of lateral branches than standard peach trees (Grassell, 1974).

Almond develops lateral branches similar to peach and perennial spurs (Gradziel, 2002), although a great diversity of tree architecture can be found in this species (Kester and Gradziel, 1990). Gradziel et al. (2002) developed a classification system for branch architecture

Received for publication 25 Apr. 2013. Accepted for publication 17 June 2013.

${ }^{1}$ To whom reprint requests should be addressed; e-mailomarcit@ufl.edu.

additional factor affecting peach tree architecture and productivity. A blind node is defined as a node lacking axillary flower and/or vegetative buds (Boonprakob et al., 1996). Blind nodes can make the training of young trees difficult and decrease potential yields in areas prone to late frosts where the crop depends on higher flower bud density to escape from poor fruit set (Richards et al., 1994).

Differences in blind node frequency among cultivars and locations can have a large impact on the pruning and potential yield in peach (Wert et al., 2007). A wide range of blind node frequency ( $0 \%$ to $90 \%$ ) has been reported for the University of Florida peach germplasm, demonstrating that there is genetic variability for blind node incidence, and breeding against this disorder should be feasible if its mode of inheritance can be determined (Richards et al., 1994).

Blind node incidence is associated with high temperatures during bud development in the midsummer (Boonprakob and Byrne, 2003; Richards et al., 1994). Fruit of low-chill peach typically ripen before summer and the subsequent vegetative growing conditions are conducive to rapid growth and high blind node frequency (Byrne et al., 2000).

Higher rates of blind nodes are observed in warmer sites like central and southwest Florida than in north-central Florida (Wert et al., 2007). Trees grown in the highlands of the subtropics or coastal climates that have cool summers do not show blind nodes but when taken to warm humid climates such as Florida often exhibit this disorder (Richards et al., 1994). Additionally, susceptible varieties do not present blind nodes in locations with hot dry summers like Sevilla, Spain, or Hermosillo, Mexico, where climatic conditions inhibit vegetative growth during the summer (Byrne et al., 2000).

Boonprakob et al. (1996) studied anatomical differences between normal and blind nodes in 'Earligrande' and 'June Gold' peach in the spring (March, April, and May) and summer (June, July, and August). Early-season shoots presented well-developed buds with the procambium connected to the stem and prophyll growth. Late-season shoots presented mostly blind nodes and anatomical observations showed that there were empty axils with partial development of stem procambium to the position of the aborted axillary buds. In some cases, an axillary meristem was observed but with very limited growth.

Little is known about the genetics and inheritance of this phenotype for peach, although previous research indicates that highly branched Prunus kansuensis and reduced branching 'Tardy Nonpareil' almond will transmit these features to their respective progenies (Carrillo-Mendoza et al., 2010). In this research we are testing that the phenotypic variation for branching and blind nodes is under genetic control.

The objective of this research was to evaluate the branching intensity and blind node incidence and determine their inheritance in interspecific Prunus backcross families.

\section{Materials and Methods}

Plant material. Seven backcross (Table 1) families were generated in 2008 and planted in Gainesville, FL. The parents were selected based on their contrasting branching intensity and blind node incidence. 'Flordaguard' rootstock $(\mathrm{FG}) \times$ Prunus kansuensis 'A' $(\mathrm{P} . \mathrm{kan})$ hybrids showed higher branch production and lower blind node incidence than FG $\times$ 'Tardy Nonpareil' almond (TNP) hybrids. Two se[chilling requirement 300 chill units $(\mathrm{CU})$ ] lections from $\mathrm{P}$. kan $\mathrm{F}_{1}$ : seedling number 3 
and seedling number 6 (300 CU), and one selection from TNP $F_{1}$ : seedling number 1260 (375 CU), were all used as male parents. One 'UF97-47' $\times$ P. kansuensis hybrid $(375$ $\mathrm{CU})$ was also selected for generating backcrosses as a male parent. The peach selections 'AP00-30WBS' (350 CU), 'UFSharp' (325 CU), and 'UF97-47' (250 CU) were used as backcross female parents. $\mathrm{FG} \times \mathrm{P}$. kan and FG $\times$ TNP hybrids backcrossed to 'AP00-30WBS' and 'UFSharp' are defined as species level backcrosses. 'UF97-47' $\times$ P. kan backcrossed to 'UF97-47' is defined as a genotype backcross.

Plant management. 'UFSharp' and 'UF9747' backcross seeds were harvested at maturity and soaked in $0.4 \%$ Captan fungicide solution, placed in a bag of moist perlite, and on the same day of harvest placed into a cold chamber at $7{ }^{\circ} \mathrm{C}$. Breeding selection 'AP0030WBS' has a fruit development period below $110 \mathrm{~d}$ and therefore required in vitro culture to ensure high germination frequency. Seeds were removed under aseptic conditions and cultured in a modified KNOPS germination media (Lyrene, 1980). The cultures were stratified in a refrigerator at $7{ }^{\circ} \mathrm{C}$ for $\approx 8$ weeks. Seeds showing radicle protrusion were planted into cone containers of sphagnum peat and perlite $(1: 1)$ containing $6 \mathrm{~kg} \cdot \mathrm{m}^{-3}$ of $15 \mathrm{~N}$ 9P-12K controlled-release fertilizer. Seedlings were grown in a greenhouse at $\approx 27{ }^{\circ} \mathrm{C}$ for 16 weeks and planted in the field in Oct. 2008 in a complete randomized block design with a total of four blocks. 'Flordaguard' rootstock seedlings were planted simultaneously with the backcross seedlings on their own roots in each block. The 'Flordaguard' rootstocks were budded in May 2009 with buds from each parent used to generate the backcrosses. Plant density was $2.10 \mathrm{~m}$ between rows and $0.6 \mathrm{~m}$ between plants within a row.

Pruning consisted of removing basal seedling suckers from the backcross trees and basal rootstock suckers from the parent trees that might interfere with weed control; other than sucker removal, trees were not pruned to keep natural branching. Four fertilizer applications were made during the growing season with $125 \mathrm{~g} /$ tree of $10 \mathrm{~N}-10 \mathrm{P}-10 \mathrm{~K}$ fertilizer in 2009 and $200 \mathrm{~g} /$ tree in 2010 . Weeds were controlled by three applications of Roundup ${ }^{\circledR}$ each growth season. Plants were irrigated in drought periods during the growing season at weekly intervals.

Branching index data collection. Data for total number of first-order branches and total number of second-, third-, and fourth-order branches from three randomly and representative selected first-order branches located on the lower, intermediate, and upper parts of each tree were obtained during the winters of 2010 and 2011. Branching index was calculated for each tree with the following formula (Carrillo-Mendoza et al., 2010):

$$
\mathrm{BI}=\prod_{i=1}^{k} 2^{\left(x_{i}+\frac{n_{i}}{100}\right)}
$$

where $x=\operatorname{absence}(x=0)$ or presence $(x=1)$ of first-, second-, third-, or subsequent-order branches; $\mathrm{n}=$ number of branches within a branching order; and $\mathrm{k}=$ the maximum order of branching.

The branching index formula used for this research is the multiplication of partial index values for each branching order existent within the tree: first-order branches that arise from the main axes, second-order branches arising from first-order branches, and so on. The branching index was validated doing regression analysis with the total number of first, second and consecutive branching orders for 2 years obtaining a $r^{2}$ value of 0.7 (Carrillo-Mendoza et al., 2010). The branching index helps to estimate branching intensity without having to count every single branch of each tree in the field.

For illustration purposes, the following scenarios of how the branching index works are presented: Trees having no branches would present BI values of 1 . Trees having only firstorder branches; first- and second-order branches; and first-, second-, and third-order branches would present values of $2<\mathrm{BI}<4,4<\mathrm{BI}<8$, and $8<\mathrm{BI}<16$, respectively. For instance, a tree with a single stem (no branches at all) would result in the Eq. $2^{[0+(0 / 100)]}$ and yield a value of 1 . For a tree having four primary branches and no higher-order branches, the Eq. $2^{[1+(4 / 100)]}$ would yield a value 2.05 . The branching index for a tree having four primary and three secondary branches would be calculated as $2^{[1+(4 / 100)]} \times 2^{[1+(3 / 100)]}$ and yield a value of 4.18 .

Trunk diameter was measured at the crown of the tree with a caliper and tree height with a ruler in the winter of 2010 and 2011 to aid as covariates for the branching index.

Blind node data collection. Blind node frequency was measured as the percentage of blind nodes from the total number of nodes in the uppermost 50 nodes of the main axis of the tree and the percentage of blind nodes from three randomly selected lateral branches that grew the previous season. These branches were chosen because they represent the genotype and genotype $\times$ environmental interaction from the previous growing season.

Identification of selfs. Six simple sequence repeat (SSR) markers used for mapping were also used to distinguish and separate contaminating progeny originating from self-pollination from true backcross progeny (Table 2). Selfed trees were excluded for data analysis.

Genomic DNA was extracted from leaf tissue of all the individuals within each backcross family (Table 1) using the CTAB method (Doyle, 1991); DNA isolation was confirmed by electrophoresis at $120 \mathrm{~V}$ for $60 \mathrm{~min}$ on a $1 \%$ agarose gel stained with ethidium bromide and TBE buffer [ $10.8 \mathrm{~g}$ Tris Base, $5.5 \mathrm{~g}$ boric acid, $4 \mathrm{~mL}$ 0.5M EDTA (pH 8.0)]. Lambda DNA of 5, 25, 50, and $100 \mathrm{ng} \cdot \mu \mathrm{L}^{-1}$ was loaded next to the samples to obtain a visual estimate of the concentration of isolated DNA. The gel was photographed on a transilluminator and afterward DNA concentration was determined by spectrophotometry. Genomic DNA from the parents was amplified by polymerase chain reaction (PCR) using six polymorphic SSRs that differentiated selfs from true backcrosses (Table 2). SSR markers that segregated for alleles that differed by less than 4 bp were amplified using labeled primers. PCR was carried out in a total volume of $10 \mu \mathrm{L}$ containing $1 \mu \mathrm{L} 10 \times$ ThermoPol Reaction Buffer $\left[10 \mathrm{~mm} \mathrm{KCl}, 10 \mathrm{~mm}(\mathrm{NH} 4)_{2} \mathrm{SO}_{4}, 20 \mathrm{~mm}\right.$ Tris- $\mathrm{HCl}, 2 \mathrm{~mm} \mathrm{MgSO}_{4}, 0.1 \%$ Triton X-100, $\mathrm{pH} 8.8$ at $25{ }^{\circ} \mathrm{C}$ ], $1 \mu \mathrm{L} 5 \mu \mathrm{M}$ forward primer, $1 \mu \mathrm{L} 5 \mu \mathrm{M}$ reverse primer, $0.8 \mu \mathrm{L}$ $2.5 \mathrm{~mm}$ dNTP, $0.2 \mu \mathrm{L}$ Taq DNA polymerase, $3 \mu \mathrm{L}$ DNA-grade water, and $3 \mu \mathrm{L} \approx 10$ $\mathrm{ng} / \mu \mathrm{L}$ DNA. PCR reactions were done on an Eppendorf ${ }^{\circledR}$ thermal cycler using the following cycling parameters: initial denaturation for 3 min at $94{ }^{\circ} \mathrm{C}$ followed by 40 cycles of $30 \mathrm{~s}$ at $94{ }^{\circ} \mathrm{C}, 30 \mathrm{~s}$ at the primer specific annealing temperature, and $1 \mathrm{~min}$ at $72{ }^{\circ} \mathrm{C}$; and a final extension of $7 \mathrm{~min}$ at $72{ }^{\circ} \mathrm{C}$. PCR products were separated on a $3.5 \%$ electrophoresis agarose gel stained with ethidium bromide

Table 1. Total number of progeny and number of contaminating self-pollinated progeny in the interspecific backcross families used for studies in branching and blind nodes.

\begin{tabular}{lcc}
\hline Family & Individuals (no.) & Selfs (no.) \\
'AP00-30wbs' $\times(\mathrm{FG} \times$ P. kan 3) & 40 & 8 \\
'AP00-30wbs' $\times(\mathrm{FG} \times$ P. kan 6) & 39 & 12 \\
'AP00-30WBS' $\times(\mathrm{FG} \times \mathrm{TNP})$ & 69 & 13 \\
'UFSharp' $\times(\mathrm{FG} \times$ P. kan 3) & 50 & 12 \\
'UFSharp' $\times(\mathrm{FG} \times$ P. kan 6) & 100 & 18 \\
'UFSharp' $\times(\mathrm{FG} \times \mathrm{TNP})$ & 113 & 24 \\
'UF97-47' $\times($ 'UF97-47' $\times$ P. kan $)$ & 56 & 9 \\
\hline
\end{tabular}

FG = 'Flordaguard' peach; P. kan = Prunus kansuensis; TNP = 'Tardy Nonpareil’ almond.

Table 2. Microsatellite markers used to identify self-pollinated in the interspecific backcross populations studied.

\begin{tabular}{ll}
\hline Family & \multicolumn{1}{c}{ Simple sequence repeats } \\
\hline 'AP00-30WBS' $\times($ FG $\times$ P. kan 3) & bppct8, bppct26, bppct30, cpsct39, epdcu3382, and udp9825 \\
'AP00-30WBS' $\times($ FG $\times$ P. kan 6) & bppct8, bppct23, bppct30, pmsg2, epdcu3382, and udp9825 \\
'AP00-30WBS' $\times($ FG $\times$ TNP) & bppct8, bppct26, bppct30, cpsct39, pmsg2, and udp9825 \\
'UFSharp' $\times($ FG $\times$ P. kan 3) & bppct14, bppct26, epdcu3382, udp968, udp98412, and udp9825 \\
'UFSharp' $\times($ FG $\times$ P. kan 6) & bppct14, bppct30, cppct33, pmsg2, udp9613, and udp9825 \\
'UFSharp' $\times($ FG $\times$ TNP) & bppct14, bppct26, cppct29, epdcu3382, pmsg2, and udp9825 \\
'UF97-47' $\times($ 'UF97-47' $\times$ P. kan $)$ & bppct8, bppct26, bppct30, cpsct39, epdcu3382, and udp9825
\end{tabular}

$\mathrm{FG}=$ 'Flordaguard' peach; P. kan = Prunus kansuensis 'A'; TNP = 'Tardy Nonpareil' almond. 
at $220 \mathrm{~V}$ and observed and photographed on a transilluminator to corroborate amplification and to determine the approximate size of the amplified DNA fragments. Markers segregating for alleles that differed by more than 6 bp were visualized and genotyped by size separation after 4-h electrophoresis. Markers segregating for alleles that differed by less than $6 \mathrm{bp}$ were fluorescently labeled and detected by capillary electrophoresis. A 100x to $400 \times$ dilution of PCR product was sent to the ICBR Genetics Analysis Laboratory at the University of Florida for fragment analysis on an $\mathrm{ABI}{ }^{\circledR} 3730$ Automated Sequencer. Allelic segregation was visualized using the Soft Genetics analysis program GeneMarker ${ }^{\circledR}$ (SoftGenetics, State College, PA) Version 1.

Statistical analysis. Analysis of variance, Tukey's multiple comparisons of means, contrast estimates, $\chi^{2}$, correlation, and regression tests were performed for branching index and blind node incidence using PROC MIX in SAS ${ }^{\circledR}$ Version 9.2 (SAS Institute Inc., Cary, NC). Branching index was analyzed using blind node incidence, tree diameter, and height as covariates to assess the effect of blind nodes and tree vigor on branching. Blind node incidence data were transformed using a logarithmic function.

\section{Results and Discussion}

Branching index. Branching intensities among the parents used for developing the backcross families were not significantly different $(P \leq 0.05)$ after their first season of growth (Table 3). Significant differences were observed after the second growth season (Table 3). P. kansuensis hybrids had the highest value, the peach genotypes were intermediate, and the TNP hybrid had the lowest mean branching index values. The lack of significance in 2010 could be the result of the short growing season the budded parental trees had in their first growth season. The trees were budded in May 2009 and had only a 6-month growing season, but there are similar tendencies to the significant results of 2011 .

The branching behavior of the parents was transmitted to the different backcross progenies for branching intensity in 2010 (Table 4). P. kan backcrosses presented the higher and TNP backcrosses had the lower branching index. P. kan hybrids backcrossed to 'UFSharp' and 'UF97-47' ranked higher, P. kan hybrids backcrossed to 'AP00-30WBS' were intermediate, and TNP hybrids backcrossed to peach ranked lower for branching. These results are similar to those obtained by Gradziel (2002) where TNP and its progeny presented limited branching relative to other almonds crossed to peach and $P$. webbii progenies. The orthogonal contrasts in Table 5 confirm the previous result, in which the effect for branching from P. kan hybrid offspring was highly significant $(P \leq 0.001)$ from that of TNP hybrid offspring. Some differences were found in the progeny generated from the different peach genotypes in 2010 (Table 5). 'UFSharp' and 'UF97-47' progeny had a higher branching index than 'AP00-30WBS'. In this case, families having TNP as a parent were not considered when compared with 'UF97-47', because 'UF97-47' was not crossed with TNP hybrids.

Branching index values for the Winter 2011 increased in all the backcross families as a result of an increment in the number of first-, second-, third-, and fourth-order branches (Fig. 1). Few individuals from the 'UFSharp' $\times$ (FG $\times$ P. kan 6) backcross families in 2010 had generated fourth-order branches and more P. kan backcross progeny presented thirdorder branches compared with TNP backcross progeny. Branching complexity increased in 2011 with a larger number of progeny having fourth-order branching and some P. kan progeny expressing an even greater branching index compared with TNP values in this category.

Transgressive segregation was found for branching index in the different backcross families suggesting that peach and almond may have alleles with different phenotypic effects at many genes controlling branching (Fig. 1).

The differences found in 2010 were conserved among the different families in 2011 $(P \leq 0.05)$ (Table 4$)$. The $\mathrm{FG} \times \mathrm{P}$. kan and
'UF97-47' $\times$ P. kan offspring branched more profusely than FG $\times$ TNP offspring. The orthogonal contrasts show that $\mathrm{P}$. kan progeny had significantly higher branching ( $P \leq$ 0.001 ) than TNP (Table 6) and that there were no differences among the peach genotypes although 'AP00-30WBS' had reduced branching in 2010 when compared with the other two selections. In general, P. kan progeny developed more profuse branching, and almond progeny developed less complex and lower branching. These results imply the potential of TNP or similar almonds in breeding for less twiggy peach trees that would be easier to prune (Gradziel, 2002).

Almond produces spurs rather than long shoots as peach; in this study, TNP hybrids and backcrosses showed less spur production compared with TNP parent, but still, the TNP parent tends to have a more open canopy with less complicated branching observed among the TNP backcross offspring.

The covariates, blind node incidence, and tree height did not appear to have a significant effect on branching index $(P \leq 0.05)$. However, tree trunk diameter had a significant effect. In addition, a positive and moderate

Table 3. Mean branching index and blind node incidence values for the main axis (BNM) and lateral branches (BNL) of the parental genotypes (winter of 2010 and 2011).

\begin{tabular}{|c|c|c|c|c|c|c|}
\hline \multirow[b]{2}{*}{ Parent } & \multicolumn{2}{|c|}{ Branching index } & \multicolumn{2}{|c|}{ BNM (\%) } & \multicolumn{2}{|c|}{ BNL (\%) } \\
\hline & 2010 & 2011 & 2010 & 2011 & 2010 & 2011 \\
\hline$\overline{\mathrm{FG} \times \mathrm{P} . \text { kan } 3}$ & $6.8 \mathrm{a}^{\mathrm{z}}$ & $21.0 \mathrm{a}$ & $6.8 \mathrm{~b}$ & $2.2 \mathrm{~b}$ & $7.4 \mathrm{~b}$ & $4.0 \mathrm{~b}$ \\
\hline $\mathrm{FG} \times \mathrm{P}$. kan 6 & $5.5 \mathrm{a}$ & $17.8 \mathrm{ab}$ & $1.7 \mathrm{~b}$ & $7.5 \mathrm{~b}$ & $3.4 \mathrm{~b}$ & $2.8 \mathrm{~b}$ \\
\hline $\mathrm{FG} \times \mathrm{TNP}$ & $3.8 \mathrm{a}$ & $6.6 \mathrm{~b}$ & $13.3 \mathrm{ab}$ & $14.8 \mathrm{ab}$ & $11.6 \mathrm{ab}$ & $19.8 \mathrm{ab}$ \\
\hline 'AP00-30WBS' & $6.1 \mathrm{a}$ & $10.0 \mathrm{ab}$ & $60.0 \mathrm{a}$ & $53.3 \mathrm{ab}$ & $54.3 \mathrm{a}$ & $57.0 \mathrm{a}$ \\
\hline 'UFSharp' & $6.5 \mathrm{a}$ & $13.2 \mathrm{ab}$ & $44.1 \mathrm{a}$ & $77.5 \mathrm{a}$ & $48.1 \mathrm{a}$ & $71.4 \mathrm{a}$ \\
\hline 'UF97-47' & $7.2 \mathrm{a}$ & $10.5 \mathrm{ab}$ & $2.5 \mathrm{~b}$ & $17.5 \mathrm{ab}$ & $2.9 \mathrm{~b}$ & $16.3 \mathrm{ab}$ \\
\hline 'UF97-47' × P. kan 3 & $7.8 \mathrm{a}$ & $17.8 \mathrm{ab}$ & $3.3 \mathrm{~b}$ & $1.1 \mathrm{~b}$ & $1.7 \mathrm{~b}$ & $0.0 \mathrm{~b}$ \\
\hline
\end{tabular}

${ }^{2}$ Means followed by different letters are significantly different, Tukey $(P \leq 0.05)$.

FG = 'Flordaguard' peach; P. kan = Prunus kansuensis; TNP = 'Tardy Nonpareil' almond.

Table 4. Mean branching index and blind node incidence for the main axis (BNM) and lateral branches (BNL) in the interspecific backcross families (winter of 2010 and 2011).

\begin{tabular}{|c|c|c|c|c|c|c|}
\hline \multirow[b]{2}{*}{ Parent } & \multicolumn{2}{|c|}{ Branching index } & \multicolumn{2}{|c|}{ BNM $(\%)$} & \multicolumn{2}{|c|}{ BNL $(\%)$} \\
\hline & 2010 & 2011 & 2010 & 2011 & 2010 & 2011 \\
\hline 'AP00-30WBS' $\times(\mathrm{FG} \times$ P. kan 3) & $5.7 \mathrm{ab}^{\mathrm{z}}$ & $17.3 \mathrm{ab}$ & $20.5 \mathrm{~b}$ & $27.7 \mathrm{bc}$ & $18.4 \mathrm{~b}$ & $24.4 \mathrm{~b}$ \\
\hline 'AP00-30 WBS' $\times(\mathrm{FG} \times \mathrm{P} . \operatorname{kan} 6)$ & $5.6 \mathrm{ab}$ & $20.7 \mathrm{a}$ & $24.9 \mathrm{~b}$ & $30.1 \mathrm{~b}$ & $21.3 \mathrm{ab}$ & $28.4 \mathrm{~b}$ \\
\hline 'AP00-30WBS' $\times(\mathrm{FG} \times \mathrm{TNP})$ & $3.9 \mathrm{~b}$ & $9.5 \mathrm{~b}$ & $34.5 \mathrm{ab}$ & $46.1 \mathrm{ab}$ & $32.1 \mathrm{a}$ & $43.5 \mathrm{a}$ \\
\hline 'UFSharp' $\times(\mathrm{FG} \times$ P. kan 3$)$ & $7.3 \mathrm{a}$ & $19.8 \mathrm{a}$ & $18.4 \mathrm{bc}$ & $27.9 \mathrm{~b}$ & $14.5 \mathrm{bc}$ & $23.3 \mathrm{bc}$ \\
\hline 'UFSharp' $\times(\mathrm{FG} \times$ P. kan 6$)$ & $8.2 \mathrm{a}$ & $18.6 \mathrm{a}$ & $23.2 \mathrm{~b}$ & $30.3 \mathrm{~b}$ & $18.4 \mathrm{~b}$ & $26.7 \mathrm{~b}$ \\
\hline 'UFSharp' $\times(\mathrm{FG} \times \mathrm{TNP})$ & $5.2 \mathrm{~b}$ & $11.9 \mathrm{~b}$ & $44.4 \mathrm{a}$ & $55.9 \mathrm{a}$ & $34.4 \mathrm{a}$ & $52.4 \mathrm{a}$ \\
\hline 'UF97-47' × ('UF97-47' × P. kan $)$ & $8.3 \mathrm{a}$ & $21.3 \mathrm{a}$ & $10.7 \mathrm{c}$ & $14.1 \mathrm{c}$ & $11.5 \mathrm{c}$ & $12.9 \mathrm{c}$ \\
\hline
\end{tabular}

${ }^{\mathrm{z}}$ Means followed by different letters are significantly different, Tukey $(P \leq 0.05)$.

$\mathrm{FG}=$ 'Flordaguard' peach; $\mathrm{P} . \mathrm{kan}=$ Prunus kansuensis; $\mathrm{TNP}=$ 'Tardy Nonpareil' almond.

Table 5. Orthagonal contrasts of backcross families by parent for branching index (BI) and blind node incidence in the main axis (BNM) and lateral branches (BNL) (winter of 2010).

\begin{tabular}{lcccccr}
\hline $\begin{array}{l}\text { Parent groups } \\
\text { contrasted }\end{array}$ & $\begin{array}{c}\text { BI } \\
\text { group mean }\end{array}$ & $\begin{array}{c}P \\
\text { value }\end{array}$ & $\begin{array}{c}\text { BNM } \\
\text { group mean }\end{array}$ & $\begin{array}{c}P \\
\text { value }\end{array}$ & $\begin{array}{c}\text { BNL } \\
\text { group mean }\end{array}$ & $\begin{array}{c}P \\
\text { value }\end{array}$ \\
\hline $\begin{array}{l}P . \text { kansuensis } \\
\text { 'Tardy Nonpareil' }\end{array}$ & 7.0 & $<0.001^{\mathrm{z}}$ & 19.5 & $<0.001$ & 16.8 & $<0.001$ \\
'AP00-30WBS' & 4.0 & & 39.4 & & 33.2 & \\
'UFSharp' & 5.0 & 0.0325 & 26.6 & 0.7838 & 23.9 & 0.2529 \\
'AP00-30WBS' & 6.9 & & 28.6 & & 22.4 & \\
'UF97-47' & 5.6 & 0.0119 & 22.7 & 0.0064 & 19.8 & 0.0212 \\
'UFSharp' & 8.3 & & 10.7 & & 11.5 & \\
'UF97-47' & 7.7 & 0.0605 & 26.4 & 0.0021 & 16.4 & 0.0465 \\
\hline
\end{tabular}

${ }^{\mathrm{z} A l p h a}=0.05$. 
relationship between tree diameter and branching ( $r=0.45, P \leq 0.05)$ was found. Conversely, tree height had no association with branching $(r=0.05, P>0.05)$. These results demonstrate that there is an association between tree diameter and branching intensity. Additionally, there were significant differences $(P \leq 0.05)$ for tree trunk diameter among the backcross families (Table 7), where the 'UFSharp' $\times(\mathrm{FG} \times \mathrm{P}$. kan $)$ backcross family had the greatest average diameter. However, no significant differences were detected for tree height, demonstrating that there is a contribution from genotype to trunk diameter as well as branching. Field observations indicated that some FG $\times$ TNP offspring had low branching although they were taller than other trees, and in some cases, many $\mathrm{FG} \times \mathrm{P}$. kan offspring that were profusely branching were not tall but had a large canopy and occupied a wide space. Blind nodes in the main axis and lateral branches had a negative but low relationship with branching index $(r=-0.19$ and -0.21 , $P \leq 0.05$, respectively). This indicates that presence or absence of vegetative buds is a component of branching but does not have the greatest impact, because branching can be also a consequence of bud density, tree vigor, and strength of apical dominance.

Trees having higher blind node frequency tended to have lower branching, resulting in trees showing open architecture and more light penetration. Although blind node is not desirable as a factor to reduce branching it also reduces branch replacement, flower bud production, and yield potential in peach.

Blocks did not have a significant effect on branching index, but there was a significant difference $(P \leq 0.001)$ between the 2 years of evaluation. The differences were a consequence of the increase in the number and complexity of branches, but also suggest effects from different growing seasons because the 2-year data correlate moderately $(r=0.58, P \leq 0.05)$. As a consequence, additional growing seasons for evaluation for branching may be useful.

Blind nodes. The parents chosen for originating the backcross progeny had significant differences $(P \leq 0.05)$ in the incidence of blind nodes on the main axis and lateral branches. The peach selections 'AP00-30WBS' and 'UFSharp' demonstrated the highest incidence in 2010 and 2011 (Table 3), whereas $\mathrm{FG} \times \mathrm{TNP}$ was intermediate and all P. kan hybrids had the lowest percentage of blind nodes. The incidence of blind nodes in 'UF9747' peach was similar to that of the FG $\times$ P. kan hybrids in 2010; however, in 2011, the frequency increased to a level similar to the FG $\times$ TNP hybrids, indicating a significant environmental effect.

Backcross families as well as the parents showed significant differences $(P \leq 0.05)$ for blind nodes in the main axis and lateral branches in 2010 and 2011 (Table 4). 'AP003 WBS' $\times($ FG $\times$ TNP $)$ and 'UFSharp' $\times(F G \times$ TNP) backcross hybrids presented the highest incidence of blind nodes, 'AP00-30WBS' $\times$ $(\mathrm{FG} \times$ P. kan $)$ and 'UFSharp' $\times(\mathrm{FG} \times \mathrm{P}$. kan $)$ backcross hybrids were intermediate, and

\section{A}

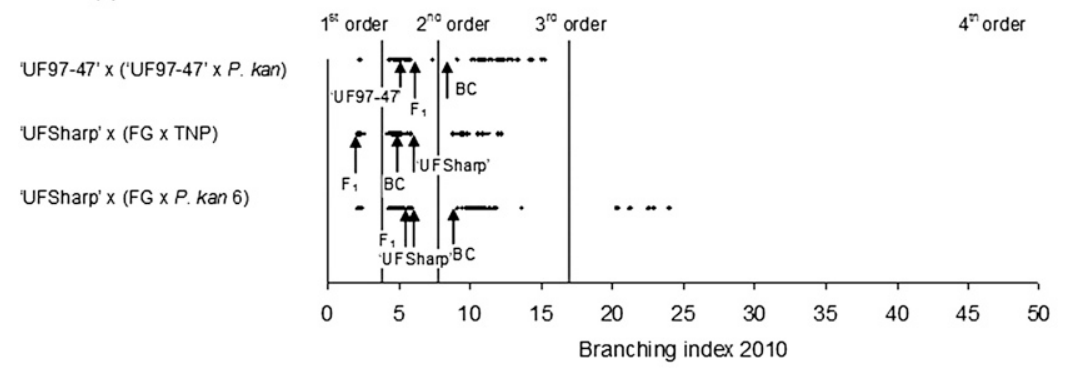

B

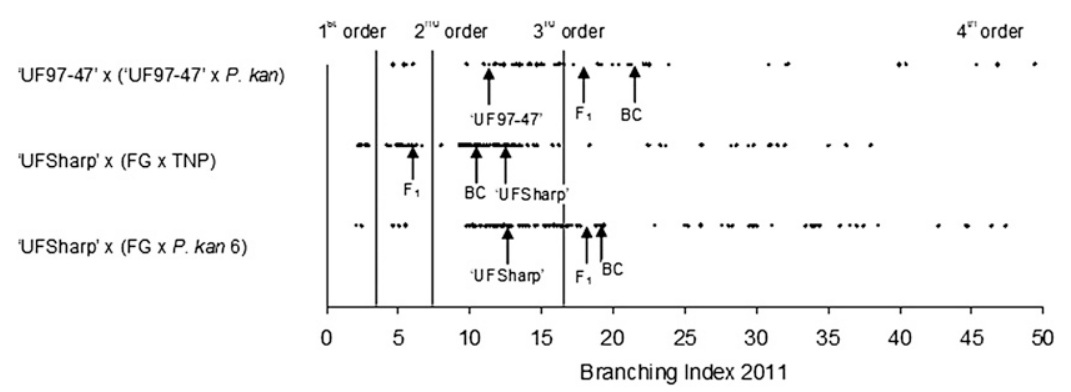

Fig. 1. Branching index values of interspecific backcross progenies in (A) 2010 and (B) 2011. Vertical lines show borders between trees having different branching orders. Arrows indicate blind node parental $\mathrm{F}_{1}$ hybrid mean (F1), backcross family mean (BC) and parental peach selection mean ('UFSharp' or 'UF97-47'). FG = 'Flordaguard' peach; P. kan = Prunus kansuensis; and TNP = 'Tardy Nonpareil' almond.

Table 6. Orthogonal contrasts of backcross families by parent for branching index (BI) and blind node incidence in the main axis (BNM) and lateral branches (BNL) (winter of 2011).

\begin{tabular}{lcccccr}
\hline $\begin{array}{l}\text { Parent groups } \\
\text { contrasted }\end{array}$ & $\begin{array}{c}\text { BI } \\
\text { group mean }\end{array}$ & $\begin{array}{c}P \\
\text { value }\end{array}$ & $\begin{array}{c}\text { BNM } \\
\text { group mean }\end{array}$ & $\begin{array}{c}P \\
\text { value }\end{array}$ & $\begin{array}{c}\text { BNL } \\
\text { group mean }\end{array}$ & $\begin{array}{r}P \\
\text { value }\end{array}$ \\
\hline $\begin{array}{l}P . \text { kansuensis } \\
\text { 'Tardy Nonpareil' }\end{array}$ & 19.5 & $<0.001^{\mathrm{z}}$ & 26.0 & $<0.001$ & 23.1 & $<0.001$ \\
'AP00-30 wbs' & 10.7 & & 51.0 & & 41.8 & \\
'UFSharp' & 15.8 & 0.6902 & 34.6 & 0.6477 & 32.1 & 0.9537 \\
'AP00-30WBS' & 16.7 & & 38.1 & & 34.1 & \\
'UF97-47' & 19.0 & 0.1769 & 28.9 & $<0.001$ & 26.4 & $<0.001$ \\
'UFSharp' & 21.3 & & 14.1 & & 12.9 & \\
'UF97-47' & 19.2 & 0.1032 & 26.4 & $<0.001$ & 25.0 & $<0.001$ \\
\hline
\end{tabular}

${ }^{\mathrm{z} A l p h a}=0.05$.

Table 7. Covariates measured in the interspecific backcross families (winter of 2010 and 2011).

\begin{tabular}{llllll}
\hline & \multicolumn{2}{c}{ Trunk diam $(\mathrm{mm})$} & & \multicolumn{2}{c}{ Tree ht $(\mathrm{m})$} \\
\cline { 2 - 3 } Parent & \multicolumn{1}{c}{2010} & 2011 & & 2010 & 2011 \\
'AP00-30 WBS' $\times(\mathrm{FG} \times$ P. kan 3) & $35.3 \mathrm{ab}^{2}$ & $73.08 \mathrm{ab}$ & & $2.17 \mathrm{a}$ & $5.04 \mathrm{a}$ \\
'AP00-30WBS' $\times(\mathrm{FG} \times$ P. kan 6) & $35.5 \mathrm{ab}$ & $72.32 \mathrm{ab}$ & & $2.16 \mathrm{a}$ & $4.84 \mathrm{a}$ \\
'AP00-30WBS' $\times(\mathrm{FG} \times$ TNP $)$ & $30.0 \mathrm{~b}$ & $62.00 \mathrm{~b}$ & & $2.09 \mathrm{a}$ & $4.60 \mathrm{a}$ \\
'UFSharp' $\times(\mathrm{FG} \times$ P. kan 3) & $45.6 \mathrm{a}$ & $83.66 \mathrm{a}$ & & $2.40 \mathrm{a}$ & $4.85 \mathrm{a}$ \\
'UFSharp' $\times(\mathrm{FG} \times$ P. kan 6) & $43.0 \mathrm{a}$ & $80.70 \mathrm{a}$ & & $2.60 \mathrm{a}$ & $5.32 \mathrm{a}$ \\
'UFSharp' $\times(\mathrm{FG} \times$ TNP) & $37.7 \mathrm{ab}$ & $73.20 \mathrm{ab}$ & & $2.69 \mathrm{a}$ & $5.44 \mathrm{a}$ \\
'UF97-47' $\times($ 'UF97-47' $\times$ P. kan $)$ & $39.4 \mathrm{ab}$ & $70.07 \mathrm{~b}$ & & $2.12 \mathrm{a}$ & $4.76 \mathrm{a}$ \\
\hline
\end{tabular}

${ }^{\mathrm{z}}$ Means followed by different letters are significantly different, Tukey $(P \leq 0.05)$.

$\mathrm{FG}=$ 'Flordaguard' peach; P. kan = Prunus kansuensis; TNP = 'Tardy Nonpareil' almond.

'UF97-47' × ('UF97-47' $\times$ P. kan) backcross hybrids had the lowest incidence of blind nodes. Blind node presence in the main axis and branches are highly correlated $(r=0.90 P$ $\leq 0.05$ ) and often the incidence is slightly higher in the main axis than lateral branches.

The orthogonal contrasts between different parents used to generate the backcross progeny confirm the previous results. Differences in the frequency of blind nodes between P. kan and TNP almond progeny in
2010 (Table 5) and 2011 (Table 6) were highly significant $(P \leq 0.001)$. Among the standard peach selections, 'UF97-47' offspring had the lowest $(P \leq 0.001)$ blind node incidence when compared with 'AP0030WBS' and 'UFSharp', indicating that there is intraspecific as well as interspecific variability for blind node propensity as indicated by Richards et al. (1994).

There was high variability for blind node frequency within the backcross families. Blind 
node frequency in lateral shoots of $\mathrm{FG} \times \mathrm{P}$. kan and $\mathrm{FG} \times \mathrm{TNP}$ progeny ranged from $0 \%$ to 90\% in 2010 and 2011 (Figs. 2 and 3, respectively), showing a broad segregation for the trait in progeny derived from contrasting parents. Although the range of blind nodes was similar for both families, the means were significantly different in both years with TNP progeny having a higher mean incidence of blind nodes than P. kan progeny. The proportion of individuals that had low incidence, classified as having $0 \%$ to $30 \%$ of blind nodes, was $\approx 0.70$ in 2010 (Fig. 2) and 2011 (Fig. 3) in $\mathrm{FG} \times \mathrm{P}$. kan backcross populations. In contrast, the proportion of progeny with a low incidence of blind nodes in FG $\times$ TNP was $\approx 0.30$ in 2010 and 2011. A $\chi^{2}$ test showed that these proportions are significantly different
$(P<0.001)$ between these two families. 'UF97-47' $\times($ 'UF97-47' $\times$ P. kan) backcross had the narrowest range with $100 \%$ of individuals in the lower blind node categories in 2010 and 2011. In contrast to the two previous families, this family had less phenotypic variation; both of the parents used to generate this backcross had low average blind node frequency (Table 3 ). These results suggest that blind node frequency is under genetic control and that use of parents with low blind node frequency such as $P$. kansuensis will produce offspring with fewer blind nodes. Similar to the branching trait, transgressive segregation was observed in the backcross progeny, again suggesting that peach and $P$. kansuensis carry different alleles at multiple loci controlling the blind node trait.
There were no significant differences among blocks for blind node frequency. There were significant differences $(P \leq 0.05)$ for blind nodes in the main axis and lateral branches among the 2 years of evaluation, suggesting different responses during different growing seasons. The overall mean for 2010 in the main axis and lateral shoots was $28.4 \%$ and $23.0 \%$, respectively, and for 2011 , there was an increase to $36.9 \%$ and $33.7 \%$, respectively. Nevertheless, there is an association for the incidence of blind nodes between the 2 years of evaluation $(r=0.80, P \leq 0.05)$. Variation was noticed in some trees, primarily in progeny with a blind node incidence between $10 \%$ and $70 \%$. However, trees with an incidence of $70 \%$ or more were the most constant in both years. These results indicate

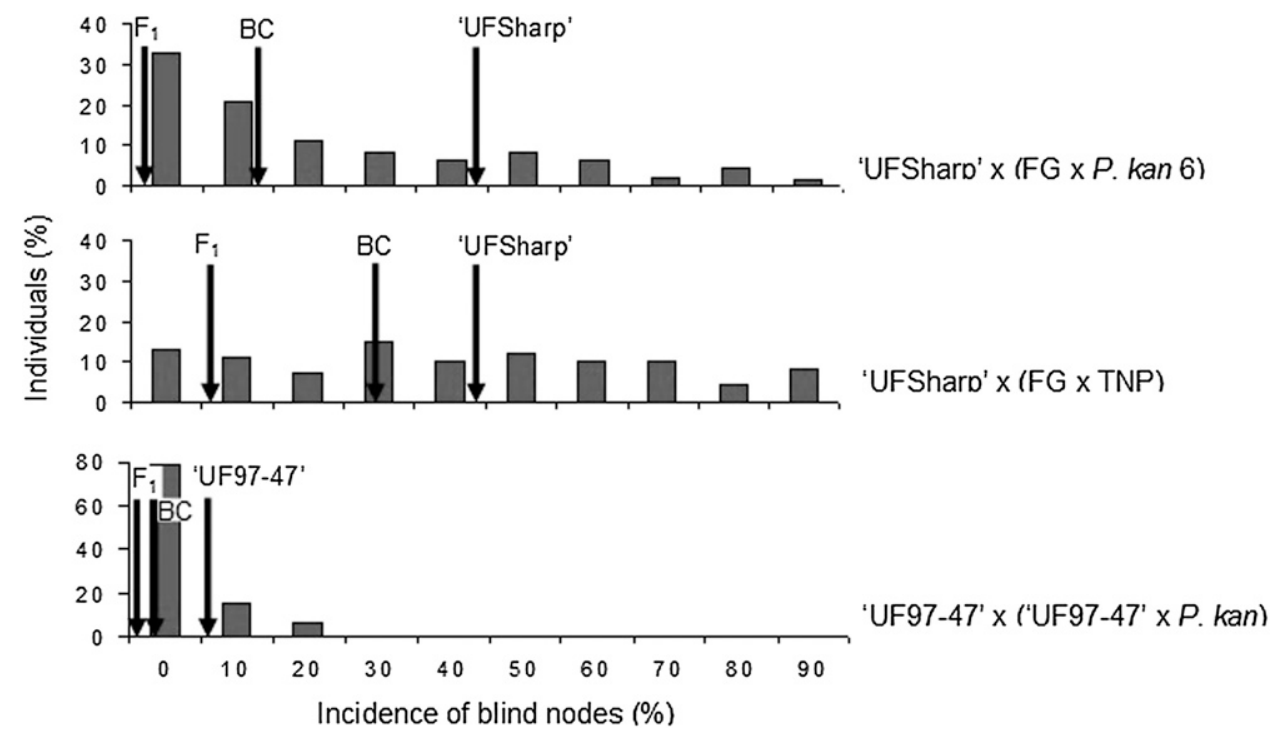

Fig. 2. Distribution of blind node incidence in lateral branches within interspecific backcross families in 2010 . Arrows indicate blind node parental $\mathrm{F}_{1}$ hybrid mean $\left(\mathrm{F}_{1}\right)$, backcross family mean (BC), and parental peach selection mean ('UFSharp' or 'UF97-47'). FG = 'Flordaguard' peach; P. kan = Prunus kansuensis; and TNP = ‘Tardy Nonpareil' almond.
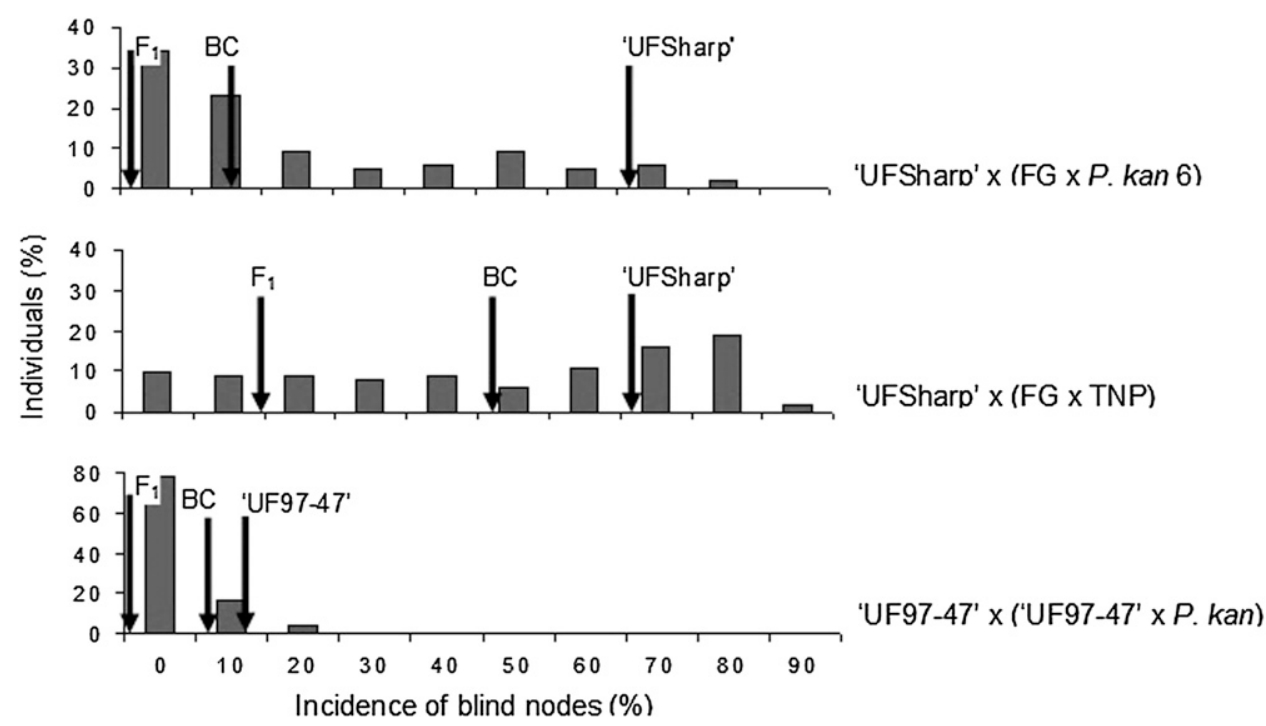

Fig. 3. Distribution of blind node incidence in lateral branches within interspecific backcross families in 2011. Arrows indicate blind node parental $\mathrm{F}_{1}$ hybrid mean $\left(\mathrm{F}_{1}\right)$, backcross family mean $(\mathrm{BC})$, and parental peach selection mean ('UFSharp' or 'UF97-47'). FG = 'Flordaguard' peach; P. kan = Prunus kansuensis; and TNP $=$ 'Tardy Nonpareil' almond. 
that a genotype with high blind node frequency will likely have the same behavior in the next seasons. On the other hand, trees with an incidence of $10 \%$ to $70 \%$ may require additional time for accurate evaluation. Individuals with the lowest incidence, $0 \%$ to $10 \%$, in 2010 or 2011 rarely had a blind node incidence above $25 \%$ in the other year, demonstrating that selection for the lowest or no incidence range is possible. There are no known thresholds for a maximum incidence of blind nodes that would risk a profitable yield, but selection for fewer blind nodes would seem prudent in climates with late spring freezes (Richards et al., 1994).

Heritability for branching and blind nodes. Narrow sense heritability was calculated by midparent-offspring regression for branching index and blind node incidence in main axis and lateral branches. Branching index narrow sense heritability was 0.37 and blind node heritabilities were 0.21 and 0.20 for main and lateral branches, respectively.

Branching index narrow sense heritability was moderate. Segura et al. (2006) reported a broad sense heritability of 0.54 for number of sylleptic branches in 1-year-old-apples; Legave et al. (2006) reported on 1-year-old apricot broad sense heritabilities of 0.71 for trunk branching, 0.51 for long sylleptic shoot branching, and 0.69 for the percentage of branching nodes. Branching and other growth traits heritability estimates for apple and apricot appear to be very variable confirming the complexity of these traits (Liebhard et al., 2003; Segura et al., 2007). Different factors such as density of lateral vegetative buds, percentage of buds that break and elongate shoots, and plant vigor affect shoot branching. Besides, different methods were used to evaluate branching. Segura et al. (2006, 2007) dissected the trait in number of sylleptic branches originated in trunk and long sylleptic shoots, number of shoots per unit of length, and percentage of branching nodes. In this study, the branching index was used as a tool to evaluate the intensity and complexity of branching as an overall mean to depict tree branching in breeding populations, giving additional explanation for the differences in heritability estimates. An additional source of variation that affected heritability was year or the two different growth seasons of evaluation, in which significant differences were found between 2010 and $2011(P \leq 0.001)$.

Despite the complex nature of branching, the data support that parents with low branching index will produce lower branching offspring, because almond backcrosses produced significantly lower branching on average compared with $P$. kansuensis backcrosses.

Blind node heritabilities were in the low range, indicating that it is a complex trait. Complex traits are influenced by many genes and the environment. Previous research has shown that summer temperatures impact the occurrence of blind nodes (Boonprakob and Byrne, 2003; Richards et al., 1994). The broad and transgressive segregation observed in the backcross families is also indicative of the complexity of this trait. There were also significant differences between the 2 years of evaluation 2010 and $2011(P \leq 0.05)$ that affected heritability.

The peach genotypes 'AP00-30WBS' and 'UFSharp' had the highest frequency of blind nodes and contributed to the broad range of segregation in the different progenies. On the other hand, the male parent's relatively small differences contributed to the differences between the families. The narrowest range of segregation was detected in the 'UF97-47' $\times($ 'UF97-47' $\times$ P. kan) backcross population (Figs. 2 and 3) where both parents had the lowest blind node frequency among standard peaches and hybrids and produced the progeny having the lowest mean incidence of this disorder. These results suggest that breeding for fewer blind nodes is possible by using parents with lower frequencies of blind nodes, although eradicating or greatly reducing this disorder in a breeding program will take several generations and high selection intensity as indicated by the low heritability estimate.

In conclusion, the $P$. kansuensis and TNP almond parents and progeny contrasted in branching and blind node propensity. P. kansuensis parents and progeny showed higher branching and lower blind node incidence compared with TNP parents and progeny, demonstrating that the traits are heritable. Low and moderate heritability estimates reveal that these are polygenic traits that are impacted by the environment. The data obtained will be used to identify quantitative trait loci and candidate genes that can be used to assist breeding for trees with low incidence of blind nodes and reduced branching.

\section{Literature Cited}

Boonprakob, U. and D.H. Byrne. 2003. Temperature influences blind node development in peach. Environmental Stress and Horticulture Crops 463-467.

Boonprakob, U., D.H. Byrne, and D.M.J. Mueller. 1996. Anatomical differences of axillary bud development in blind nodes and normal nodes in peach. HortScience 31:798-801.
Byrne, D.H., W.B. Sherman, and T.A. Bacon. 2000. Stone fruit breeding genetic pool and its exploitation for growing under warm winter conditions, p. 157-230. In: Erez, A. (ed.). Temperate fruit crops in warm climates. Kluwer Academic Publishers, Dordrecht, The Netherlands.

Carrillo-Mendoza, O., W.B. Sherman, and J.X. Chaparro. 2010. Development of a branching index for evaluation of peach seedlings using interspecific hybrids. HortScience 45:852-856.

Doyle, J.J. 1991. DNA protocols for plants. CABI, New York, NY.

Gradziel, T.M. 2002. Almond species as sources of new genes for peach improvement. Proc. of the 5th International Peach Symposium. 1:81-88.

Gradziel, T.M., D.E. Kester, and P. MartinezGomez. 2002. A development based classification for branch architecture in almond. Journal American Pomological Society 56:106-112.

Grassell, C. 1974. Study of possibilities of producing intraoperative and interspecific F1hybrids in sub-genus amygdalus. Annales de Amelioration des Plantes 24:307-315.

Kester, D.E. and T. Gradziel. 1990. Growth habit trait nomenclature in almond and peach phenotypes. HortScience 25:1072.

Legave, J.M., V. Segura, D. Fournier, and E. Costes. 2006. The effect of genotype, location and their interaction on early growth and branching in apricot trees. J. Hort. Sci. Biotechnol. 81:189198.

Liebhard, R., M. Kellerhals, W. Pfammatter, M. Jertmini, and C. Gessler. 2003. Mapping quantitative physiological traits in apple (Malus domestica Borkh.). Plant Mol. Biol. 52:511-526.

Lyrene, P.M. 1980. Micropropagation of rabbiteye blueberries. HortScience 15:80-81.

Marini, R.P. and L. Corelli-Grappadelli. 2006. Peach orchard systems. Hort. Rev. 32:63-109.

Richards, G.D., G.W. Porter, J. Rodriguez, and W.B. Sherman. 1994. Incidence of blind nodes in low-chill peach and nectarine germplasm. Fruit Varieties Journal 48:199-202.

Scorza, R., S. Miller, D.M. Glenn, W.R. Okie, and T. Tworkoski. 2006. Developing peach cultivars with novel tree growth habits. Proc. of the VIth International Peach Symposium. p. 61-64.

Scorza, R. and W.R. Okie. 1990. Peaches (Prunus). Acta Hort. 290:175-231.

Segura, V., C. Cilas, F. Laurens, and E. Costes. 2006. Phenotyping progenies for complex architectural traits: A strategy for 1-year-old apple trees (Malus $\times$ domestica Borkh.). Tree Genet. Genomes 2:140-151.

Segura, V., C. Denance, C.E. Durel, and E. Costes. 2007. Wide range QTL analysis for complex architectural traits in a 1-year-old apple progeny. Genome 50:159-171.

Sherman, W.B., P.M. Lyrene, and R.H. Sharpe. 1991. Flordaguard peach rootstock. HortScience 26:427-428.

Wert, T.W., J.G. Williamson, J.X. Chaparro, and E.P. Miller. 2007. Node type development of four low-chill peach cultivars at three locations in Florida. HortScience 42:1592-1595. 